\title{
Recepção da poesia erótica latina no séc. XIX: José Feliciano de Castilho e sua edição dos Amores, de Ovídio*
}

Brunno V. G. Vieira

FCLAR/ UNESP

brvieira@fclar.unesp.br

\begin{abstract}
This paper presents some results of the research project "José Feliciano de Castilho and classical tradition in the 19th Century", financed by FAPESP. My aim is to offer a presentation to the "Grinalda Ovidiana", a large commentary to Ovid's Amores that ends up the paraphrastic translation of romantic poet Antônio Feliciano de Castilho published in Rio de Janeiro in 1858. The wise comments of José Feliciano de Castilho constitute a concrete evidence of the reception of ancient Latin Literature during the "Segundo Reinado". Some considerations about how Castilho Antônio and Castilho José read and translated erotic classical poetry will be made too.

KEYWORDS: José Feliciano de Castilho; Antônio Feliciano de Castilho; receptions of classical poetry; translation studies.
\end{abstract}

José Feliciano de Castilho Barreto e Noronha (1810-1879), cognominado no meio jornalístico e literário, ora por Castilho José, ora por José Feliciano de Castilho, é um distinto luso-brasileiro - como bem definiu seu biógrafo Hélio Vianna ${ }^{1}$ - que viveu no Rio de Janeiro de 1847 até sua morte em 1879, tendo atuado na cena literária desse período como jornalista, filólogo, educador e latinista.

Da sua produção em solo brasileiro, convém destacar no âmbito filológico a edição dos "excerptos" dos quinhentistas Fernão Mendes Pinto (1865) e João de Lucena (1868), bem como dos "excerptos" de Bocage em três volumes, que comportam também um longo estudo bio-bibliográfico (1867); ressalte-se também seu pioneirismo no campo da ecdótica, verificável em seus estudos sobre o exemplar d'Os Lusíadas da biblioteca de D. Pedro II (redigido em 1848 e publicado em 1881) e sobre o Missal de Estevam Gonçalves (1874). No meio educacional, editou, em 1860, a antologia escolar mais utilizada no período, o Íris Clássico, e, em defesa da ortografia etimológica - pela qual propugnava -, redigiu no mesmo ano Ortografia portuguesa e missão dos livros elementares. No jornalismo, além de redigir quase sozinho o periódico Íris (entre 1848 e 1849), que Raimundo Menezes destaca como "um dos melhores do período", 3 destacou-se pela renhida polêmica contra José de Alencar sobre questões de língua dos

\footnotetext{
* Artigo resultante de trabalho de pesquisa apoiado pela FAPESP.

${ }^{1}$ Cf. Vianna, H. Um intelectual português na corte de D. Pedro II: José Feliciano de Castilho Barreto e Noronha. Brasília. Coimbra, vol. V, p. 466, 1950.

${ }^{2}$ Cf. Referências ao final deste artigo para citações completas dos textos de Castilho José.

${ }^{3}$ Cf. de Menezes, R. Dicionário literário brasileiro. Rio de Janeiro: Liv. téc. e cient., 1978, p. 178.
} 
romances Iracema e $O$ Gaúcho, refrega que ainda hoje é responsável pela presença de seu nome em grande parte das histórias da literatura brasileira.

Entre essas não poucas obras, têm lugar importantes edições de traduções latinas como a dos Amores (1858) e a d'A arte de amar (1862), ${ }^{4}$ de Ovídio, traduzidas pelo seu ilustre irmão Antônio Feliciano de Castilho (1800-1875) com organização e notas do próprio Castilho José, mas também há versões da lavra deste último, como os excertos da Farsália, de Lucano (a saber, os cantos I, VI, VII e metade do X), que vieram a lume em jornais e revistas do período, e outras tantas espalhadas pelas anotações aos textos ovidianos supracitados. Dentre essas, os adágios de Públio Siro, que se encontram na "Grinalda da Arte de Amar", 5 são um bom exemplo.

Tenho trabalhado ultimamente na edição das traduções de Castilho José encontradas nas suas "Grinaldas" e, em especial, na recuperação das versões da Farsália saídas em revistas e jornais da época, material que será objeto de futuras publicações. Procurando divulgar a obra desse autor, como prelúdio ao trabalho de transcrição e atualização de seus textos que venho desenvolvendo, meu objetivo, neste breve artigo, ${ }^{6}$ é fornecer algumas notas de leitura à edição dos Amores, de Ovídio, e à "Grinalda Ovidiana" que a segue. Mais que propor um contraste com nossa atual visão da obra ou censurar alguns de seus senões interpretativos, desejo reconduzir à luz essa edição dos Amores de 1858, um consistente testemunho da leitura de Ovídio no Brasil do séc. XIX.

O ano de 1858, aliás, pode ser visto como um marco do classicismo vigente sob D. Pedro II, já que nessa data foram publicados o Virgílio brasileiro de Odorico Mendes ${ }^{7}$ e os Amores, de Ovídio. ${ }^{8}$ Se a história da tradução do legado greco-romano, que vem-se consolidando nos últimos anos, já conta com a reedição das traduções do Virgílio odoricano, ainda um grande silêncio paira sobre a monumental edição dos

\footnotetext{
${ }^{4}$ No séc. XX, tanto os Amores quanto a Arte de Amar mereceram reedição, mas apenas com o texto da tradução de Castilho Antônio. As fartas anotações de Castilho José foram ignoradas por completo (cf. Ovídio. Obras; Os Fastos; Os amores; A arte de amar. Tradução de A. F. Castilho. São Paulo: Edições Cultura, 1945). Na década de 1990, houve uma reedição - novamente apenas da tradução - da Arte de Amar, que contou em seu Prefácio com uma avaliação bastante positiva da versão castilhiana, a cargo da classicista Zelia de Almeida Cardoso (cf. Ovídio. Arte de amar. Prefácio de Z. de A. Cardoso, tradução de N. Correia e D. Mourão-Ferreira, apêndice com a tradução erudita de A. F. Castilho. São Paulo: Ars poetica, 1992).

${ }^{5}$ Cf. Ovídio. Arte de amar de Publio Ovidio Nasão. Tradução de A. F. de Castilho seguidas de comentários de J. F. de Castilho. Rio de Janeiro: Laemmert, 1862, p. 202-212.

${ }^{6}$ Uma primeira versão deste trabalho foi apresentada oralmente no "XVII Congresso Nacional de Estudos Clássicos da SBEC 'Amizade e prazer no Mundo Antigo'”, ocorrido em Natal/ RN entre 21 e 25 de setembro de 2009.

${ }^{7}$ Cf. Virgílio. Eneida brasileira. Traduction de M. de O. Mendes. Paris: Tip. W. Remquet et Cie., 1858.

${ }^{8}$ Cf. Ovídio. Os amores de P. Ovídio Nasão. Paráfrase por Antonio Feliciano de Castilho, seguida pela "Grinalda Ovidiana", por José Feliciano de Castilho. Rio de Janeiro: Bernardo Xavier Pinto de Sousa, 1858. Vol. IV, p. 8-9.
} 
Amores de Ovídio composta pela tradução de Antônio Feliciano de Castilho em três volumes e pela "Grinalda Ovidiana" redigida por Castilho José, um compêndio de notas, comentários e interpretações do texto de Ovídio que perfazem um total de oito volumes, setecentas e oitenta e cinco páginas. É este silêncio que o presente trabalho de reavaliação pretende fazer cessar. ${ }^{9}$

O livro abre-se com uma advertência sobre a temática adulta ali tratada:

\section{ADVERTÊNCIA IMPORTANTE ADOLESCENTES DE UM E OUTRO SEXO}

Sob um título que vos poderá atrair, este livro contém mistérios de iniquidade. Se o abrísseis, depois deste pregão, só de vós mesmos vos podereis queixar. Não é para vós que foi escrito. Quem o apresentasse, ou o permitisse à inocência, só esse seria seu envenenador. ${ }^{10}$

Embora tanto Castilho Antônio em sua tradução quanto Castilho José em suas notas sirvam-se de linguagem figurada para traduzir o léxico e as ideias de sexualidade mais explícita, é um cuidado condizente com o contexto de produção da obra a necessidade de desaconselhar que o livro fosse lido por jovens leitores e leitoras. Talvez, a relação que os dois autores mantinham com os meios educacionais em Portugal e no Brasil os obrigassem a tomar esse cuidado. Sobre o caráter nefasto desses Amores, convém ainda apontar que o comentador Castilho José declara no preâmbulo do livro que o imprimiu sem autorização expressa do irmão tradutor, embora lembre que a obra fora elaborada no Brasil no ano de 1855, quando da estada de Castilho Antônio nesse país.

Sabemos que o metro das Elegias é o dístico elegíaco (composto por um hexâmetro seguido de um pentâmetro) e Castilho Antônio procura oferecer um variado mosaico de versos portugueses para tentar sinalizar a variedade métrica da estrofe latina. $\mathrm{Na}$ verdade, o tradutor, que em 1851 havia publicado seu Tratado de metrificação portuguesa, obra que consolidou um novo modo de contar sílabas métricas na tradição lusófona, usa a tradução de Ovídio como exemplário de sua Arte Poética. Castilho José bem identifica esse traço ao dizer, na "Grinalda":

\footnotetext{
${ }^{9}$ Um artigo recente (cf. Trevizam, M. Líricos greco-romanos em Portugal: algumas traduções de Almeida Garrett e Antônio Feliciano de Castilho. Revista do Centro de Estudos Portugueses. Belo Horizonte, n. 27, p. 181-202, 2007) começou a liquidar este silêncio sobre as traduções que Castilho Antônio fez do legado greco-romano. Respondendo às atuais reavaliações da tradição tradutória lusófona, Trevizam erige uma positiva leitura das versões do poeta romântico português, embora não haja referência explícita a Castilho José, nem à edição dos Amores de 1858.

${ }^{10}$ Cf. Ovídio, op. cit., 1858, vol. I, p. 5 (atualizei a grafia de todas as citações utilizadas neste artigo).
} 


\section{nuntius antiquus}

Transplantar pois para a nossa língua, em tão apropriada época, as riquezas do latim, é prestar às letras incomensurável serviço; é proporcionar modelos e guias, é excitar emulações, é estender horizontes, é robustecer uma literatura cansada e transviada. Nobre e difícil empenho é esse, de que a atual paráfrase nos dá brilhante exemplo ${ }^{11}$.

É possível verificar na tradução do primeiro poema de Amores $^{12}$ transcrita abaixo uma proposital variação quanto ao metro (no excerto verificam-se decassílabos, hexassílabos e eneassílabos) e aos arranjos estróficos dos versos:

Ser de Homero rival lembrou-me um dia; Cantar guerras, herois; e em nobres voos À grandeza do assunto alçar meus versos. Já na destra o clarim, na fronte os louros, Na mente a glória, me ensaiava aos cantos.

Riu-se Cupido... e rindo-se furtou-me

O lauréu, o instrumento;

De rosas e de murtas

C'roou-me num momento;

Pôs-me nas mãos a lira

Tão cara à mãe de Amor.

Quem te deu esse jus em poesia,

Vão menino cruel invasor?

Têm as musas em nós sob'rania;

Não são vates vassalos de Amor.

Embora minha proposta não seja analisar a tradução em si, como tenho a pretensão de resenhar a obra, importa, contudo, destacar alguns pontos fundamentais dessa paráfrase. As elegias romanas de Ovídio recebem o nome de Canções, e convém notar a atenção à tipologia genérica de Horácio utilizada para justificar tal liberdade:

Ao título de Elegias substitui o de CANÇÕES. O termo elegia não tem hoje a extensão de significação que tinha no tempo de Ovídio; reverteu à sua melancolia originária:

Versibus impariter iunctis querimonia primum, post etiam inclusa est uoti sententia compos. ${ }^{13}$

A denominação de elegia era, portanto, ininteligível, aplicada à maior parte destes poemas. $\mathrm{O}$ termo canção abrange-os a todos, tomado

\footnotetext{
${ }^{11}$ Cf. Ovídio, op. cit., 1858, vol. V, p. 180.

${ }^{12}$ Cf. Ovídio, op. cit, 1858 , vol. I, p. 41.

${ }^{13}$ Cf. Horácio. Arte poética. Introdução, tradução e notas de R. M. Rosado Fernandes. Lisboa: Livraria Clássica, 197..., v. 75-76: "Em versos desiguais jungidos veio o pranto,/ depois se insere neles a votiva prece" (minha tradução).
} 


\section{nuntius antiquus}

todavia no sentido amplo, que de propriedade lhe compete, e não naquela estreiteza mesquinha e ridícula em que o emparedaram quinhentistas e seiscentos. ${ }^{14}$

$\mathrm{Na}$ atual leitura deste passo horaciano, o testemunho de que nos seus inícios a elegia expressava o lamento não significa que sobre o mesmo nome de elegia não se compusessem depois poemas de temática amorosa. Todavia, Castilho Antônio serve-se de uma interpretação um tanto tendenciosa do passo de Horácio, de modo a adotar um nome para os poemas mais condizente com as práticas poéticas de seu tempo e com sua concepção parafrástica da tradução. ${ }^{15}$

Falando ainda das características da tradução dos Amores, vale lembrar que, entre essas Canções, estavam os primeiros poemas publicados no Brasil a se servirem largamente do alexandrino (verso de doze sílabas). Tanto era novidade que ainda em nota ao primeiro poema o comentador adverte o leitor de qual metro se trata:

Amor! Amor! lhe disse; é vã tua fadiga.

\section{Alexandrinos}

Desde os bissílabos até os dodecassílabos (ou alexandrinos) há nesta verdadeira Arte Poética numerosos exemplos; porém é a estes últimos que o ilustre tradutor se tem nas suas recentes produções com mais esmero aplicado; por tão autorizado exemplo e tão repetido conselho, já não é raro ver o emprego do alexandrino em algumas das mais distintas liras modernas. ${ }^{16}$

A respeito do influxo da "Grinalda" sobre a literatura nacional de então, cabe ressaltar que Machado de Assis, um dos precursores do uso do alexandrino entre nós, publica seu primeiro poema neste metro em $1858,{ }^{17}$ mesmo ano em que viera a lume a edição dos Castilhos. Sobre o novo metro, o próprio Castilho José polemiza com o irmão contra a obrigatoriedade da cesura na sexta sílaba ou da sinalefa entre a sétima e a oitava sílabas do alexandrino. Isso quer dizer que o dodecassílabo - como usamos chamar a variante do alexandrino sem a cesura ou sem a sinalefa obrigatórias - foi

\footnotetext{
${ }^{14}$ Cf. Ovídio, op. cit, 1858, vol. I, p. 32-33.

${ }^{15}$ A ideia de paráfrase é concebida por Castilho José a partir do famoso excerto de Cícero, no De optimo genere oratorum, XIV: Non uerbum pro uerbo necesse habui reddere, sed GENVS omne uerborum VIMQUE seruaui. Non enim ea me ANNVMERARE lectori putaui oportere, sed tamquam APPENDERE (grifo de Castilho José).

${ }^{16}$ Cf. Ovídio, op. cit., vol. VI, p. 234-235.

${ }^{17}$ Machado publicou no Correio mercantil seu primeiro poema em alexandrinos "O progresso - Hino da mocidade" em 30/ 11/ 1858. Sobre a relação da poesia machadiana com as obras de Castilho José, cf. Vieira, B. V. G. José Feliciano de Castilho e a clâmide romana de Machado de Assis. Machado de Assis em linha. Rio de Janeiro, vol. IV, p. 1-16, 2009.
} 


\section{nuntius antiquus}

concebido teoricamente no interior da "Grinalda" e o uso que, nós, tradutores de latim, temos feito do verso de doze sílabas tem em Castilho José um dos primeiros teorizadores:

Dissemos que, pelos ponderosos motivos, de mais avantajadas ensanchas, maior variedade de metro, e superior majestade do dodecassílabo, achávamos dever o seu uso ser mui recomendado; porém que as pausas, as cesuras, as partições deviam deixar-se ao libérrimo arbítrio do versejador; e que, em língua portuguesa, era inadmissível a peia da alternativa dos graves e agudos. ${ }^{18}$

Além da sedimentação teórica sobre questões métricas, outra grande contribuição que encontramos na "Grinalda" é seu aspecto antológico. Logo na introdução que antecipa seus comentários Castilho José trata de delimitar seu labor de escoliasta:

Com algumas informações miúdas, só destinadas a dar sucinta ideia de mitologias, histórias ou costumes, de outros tempos, àqueles que a não tivessem, se nos foi associando o pensamento, já de apreciar o texto, já de o confrontar, já de entesourar enfim para aqui excertos preciosos de outros poetas eróticos, em que se notava semelhança com alguns passos do romano autor, no que sem dúvida se duplica para muitos o valor da obra, e se acrescentará recreio a quem a ler. Desses autores uns são gregos, outros romanos, outros modernos (nacionais e estrangeiros). Dos gregos e romanos, o que se dá em português, sem nome de autor, é de Castilho António ou nosso. ${ }^{19}$

Observa-se, então, que além do trabalho de aclaramento de questões mitológicas, históricas e culturais, a obra procura fornecer traduções de excertos de vários autores gregos e romanos pelo critério da "semelhança" com determinados passos de Ovídio. Verifica-se, então, a adesão de Castilho José ao tipo de adnotationes que, desde Sérvio Honorato Mauro, o comentador da obra de Virgílio, tentavam explicar sistematicamente os textos clássicos a partir de relações temáticas, estilísticas e formais entre dois ou mais autores. O fato de se acrescentarem a esses comentários traduções poéticas desses intertextos realmente "duplica o valor da obra", pois a "Grinalda" acaba por se tornar uma grande antologia de poesia latina em português.

Um bom exemplo dessa perspectiva antológica está presente no comentário à elegia I, 8, de Ovídio. O poema trata da feiticeira Dipsas, que expõe a uma jovem

\footnotetext{
${ }^{18}$ Cf. Ovídio, op. cit., 1858, vol. VI, p. 236-237.

${ }^{19}$ Cf. Ovídio, op. cit., 1858, vol. IV, p. 8-9.
} 
amante um catálogo de artimanhas amorosas, advertindo-a sobre como tirar proveito de um homem enamorado. Nos primeiros vinte e dois versos latinos (vinte e nove na tradução), o eu-lírico descreve a feiticeira fazendo uso de vasta erudição literária sobre o tema. Visivelmente interessado, Castilho José dedica trinta e seis páginas a explicações sobre detalhes de ritos mágicos e a poemas ou excertos traduzidos por ele de Propércio (Elegia VI, 5 - 78 v.), Virgílio (Bucólica VIII, 64-109 - 45 v.), Lucano (Pharsalia VI, 438-569 - 131 v.), Sêneca (Hércules no Eta, diálogo do II ato - 24 v.) e Marcial (Epigrammata IX, 30 - 12 v.), sem falar na incorporação de um trecho de uma Cantata de Bocage (26 v.) sobre Medeia e da tradução de Seabra da Sátira I, VIII de Horácio (48 v.).

Uma questão relevante que urge ser levantada é a da autoria das traduções presentes na "Grinalda Ovidiana". Como se vê na transcrição acima, Castilho José afirma que as traduções sem autor manifesto serão dele ou de Castilho Antônio. Na verdade, o que pude perceber é que a declaração de autoria é sempre explicitada, como confirmam essas traduções constantes no comentário da elegia I, 8: a elegia VI, 5 de Propércio é introduzida por "eis aqui a versão de Propércio"; ${ }^{20}$ o excerto da Bucólica de Virgílio é apresentado por "desculpe-se a seguinte tentativa de versão"; "tentemos dálo em vulgar" ${ }^{, 2}$ prefacia a tradução de Lucano; e, por fim, o trecho de Sêneca vem traduzido como continuação do argumento de Hércules no Eta: "No segundo ato notase o seguinte diálogo". ${ }^{23}$ Então, se é Castilho José, como sabemos, que escreve esses comentários, as traduções são de sua lavra. No caso da autoria ser de Castilho Antônio ou de qualquer outro tradutor, há sempre declaração expressa.

Ora, muitos dos poemas latinos cuja tradução é atribuída atualmente a Castilho Antônio foram na verdade vertidos por Castilho José. Na antologia Poesia da coleção "Clássicos Jackson" - muito trivial nos sebos de hoje, mas sinal de prestígio na década de sessenta,$-{ }^{24}$ uma obscura, senão ambígua, delimitação de autoria feita por Mesquita entre aquelas traduções atribuídas a "A. F. de Castilho" e a "Castilho" - isto é, José Feliciano de Castilho - levou a uma confusão de nomes que favorece o primeiro. É importante que se diga, entretanto, que os poemas de Catulo e Marcial estampados

\footnotetext{
${ }^{20}$ Cf. Ovídio, op. cit., 1858, vol. VIII, p. 438.

${ }^{21}$ Cf. Ovídio, op. cit., 1858, vol. VIII, p. 447.

${ }^{22}$ Cf. Ovídio, op. cit., 1858, vol. VIII, p. 453.

${ }^{23}$ Cf. Ovídio, op. cit., 1858, vol. VIII, p. 462.

${ }^{24}$ Cf. Mesquita, A. (org.). Poesia. São Paulo: W. M. Jackson, 1956. Vol. I. Há reedição mais recente pela Ediouro [cf. Mesquita, A. (org.). O livro de ouro da poesia universal. 30 séculos de poesia do século IX a.C. até o século XX. Rio de Janeiro: Ediouro, 1988].
} 
naquela antologia têm como fonte a "Grinalda Ovidiana" e seu tradutor é de fato Castilho José. $^{25}$

Deixo as discussões em torno dos gestos tradutórios e me encaminho já para o final deste artigo, procurando mostrar como Castilho José interpretava as manifestações do erotismo presentes nas obras da Antiguidade Clássica. Sua definição do "amor" em Roma segue a leitura da História Universal de Cantù, ${ }^{26}$ historiador que, se hoje é desacreditado pelo seu dogmatismo cristão, à época era bastante respeitado:

Os romanos casavam sem amor, e seu amor foi sempre indelicado. Amor na língua deles, quer dizer: libertinagem. Dion (L. XI, 4) diz que Nero "comia, embriagava-se, amava". Tinham eles este brutal anexim: "Sem Ceres e Baco, o frio ataca Vênus". Dizia o censor Metelo Numídico: "Houvesse a natureza sido menos madrasta, dandonos a vida sem precisão de mulher, e ver-nos-íamos livres de bem importuna companhia!" Acrescentava mais, que o casamento devia considerar-se como o sacrifício de um prazer particular a um dever público (Aulo Gélio, I). ${ }^{27}$

É possível notar nessa interpretação do amor romano como "indelicado" uma tendência à censura dos costumes pagãos. Mas não nos enganemos, Castilho José mostra surpreendente preocupação quanto aos anacronismos. Diz ele mesmo que "é indispensável, para bem avaliarmos estes quadros de outras eras, que nos coloquemos no seu ponto de vista verdadeiro, que está bem longe de ser o nosso". ${ }^{28}$ Há que se ressaltar, nesse sentido, a propriedade filológica de entender o amor em Roma por "libertinagem" - uma de suas acepções.

Na continuação, Castilho José traça um perfil da mulher romana e parece que a intenção dele é mostrar a afinidade entre o perfil das figuras femininas presentes na poesia erótica latina com personagens históricas. Cita-se, então, uma listagem de famosos casos de má conduta e devassidão femininos como o de Cornélia, Otávia, Sevília, Sila, Tulíola - filha de Cícero, a quem acusa ter tido relações amorosas com o próprio pai -, Múcia, Sáxia, Clódia, Citérida - prostituta que ficou ao lado de Marco Antônio em um desfile triunfal - e Fúlvia. Nota-se, assim, uma supervalorização dos

\footnotetext{
${ }^{25}$ Reivindico, portanto, a autoria de Castilho José para as traduções dos poemas 2 e 85 de Catulo (cf. Mesquita, op. cit., 1956, p. 34-35 ), bem como dos epigramas VIII, 64 e IV, 38 de Marcial (cf. Mesquita, op. cit., 1956, p. 85-86).

${ }^{26}$ A alusão à citação do texto de Cantù é introduzida assim por Castilho José: "Permita-se-nos repetir o que diz Cantù, na sua História Universal; para que falarmos diversamente quando tão bem o não faríamos?" (cf. Ovídio, op. cit., 1858, vol. V, p. 172).

${ }^{27}$ Cf. Ovídio, op. cit., 1858, vol. V, p. 172.

${ }^{28}$ Cf. Ovídio, op. cit., 1858, vol. V, p. 111.
} 
Amores como fonte histórica, o que leva o comentador se fiar em uma precipitada avaliação generalizadora.

A interpretação que Castilho José fornece sobre Corina, contudo, bem merece a consideração do leitor moderno pela proximidade que tem com avanços interpretativos do gênero elegíaco que até então eu julgava serem frutos do séc. XX. Castilho José se arvora contra o ilustre latinista francês Nisard em defesa de uma interpretação literária do romance vivido pelo eu-lírico e sua amante. Seus argumentos são bastante sólidos e firmados em uma leitura douta do próprio Ovídio que nos fala nos Tristia, em conhecido poema auto-biográfico, sobre sua paixão por um falso...amore e sobre o fato de ser mendax et ficta grande parte do que cantara em suas obras. ${ }^{29}$

Quanto à ideia de um falso nome Castilho José lembra a perspectiva genérica de tal escolha, aludindo-se a outros poetas elegíacos latinos. Já quanto à evocada ficção da obra ovidiana, Castilho José propugna pela ideia de que Corina não é uma mulher real, mas a soma de várias, a própria "feminidade", ousando dizer mais à frente quando recupera a alusão à poetisa da Beócia que ela é a própria "poesia erótica": "A Corina tebana havia sido denominada 'A musa lírica'. É a própria musa lírica, que Ovídio põe em cena mais de uma vez. Corina significa, pois: beleza, amor, poesia erótica". ${ }^{30}$

Como procurei demonstrar aqui, pela quantidade e a qualidade das traduções greco-romanas da "Grinalda Ovidiana", bem como pelo teor dos ousados exercícios interpretativos ali encontrados, Castilho José expressa um domínio da cultura clássica e um apuro filológico que merecem ainda um digno reconhecimento.

\section{Referências}

de ASSIS, M. Toda poesia de Machado de Assis. Organização de C. M. Leal. Rio de Janeiro: Record, 2008.

CASTILHO, J. F. A "Farsália" de Lucano: livro VII, A Batalha de Farsália. Archivo Pitoresco. Lisboa, vol. VII, p. 198-200/ p. 206-207/ p. 214-216/ p. 222-224/ p. 231-232, 1864.

\footnotetext{
${ }^{29}$ Sobre o entendimento ovidiano de sua persona erótica, convém apontar uma passagem de Tristes, transcrita em latim na própria "Grinalda": Ad leue rursus opus, iuuenilia carmina, ueni,/ et falso moui pectus amore meum - "Obras ligeiras, versos juvenis, voltei,/ meu peito sofre já de amor fingido" (Ovídio, Tristia II 1, 339-340)./ Magnaque pars mendax operum est et ficta meorum"Grande parte dos meus versos é mentirosa e inventada" (Ovídio, Tristia II 1, 355, as traduções são minhas).

${ }^{30}$ Cf. Ovídio, op. cit., 1858, vol. V, p. 136.
} 
Cesar no Egypto: excerpto da traducção inedita da "Pharsalia" de Lucano - Principio do livro X. Revista contemporanea de Portugal e Brazil. Lisboa, vol. IV, p. 289-296/ p. 467-472, 1862.

. (org.) Íris. Periódico de Religião, Belas-Artes, Ciências, Letras, História, Poesia, Romance, Notícias e Variedades. Periodicidade quinzenal. Volumes disponíveis na Biblioteca Nacional. Rio de Janeiro, anno I, n.1, 15 de fevereiro de 1848/ anno II, n. 27, 30 de junho de 1849 (num total de 27 fasc.).

. Estudo sobre o Missal de Estevam Gonçalves. Rio de Janeiro: Tip. Americana, 1874.

. Memória sobre o exemplar dos "Lusíadas" da biblioteca particular de S. M. o Imperador. Anais da Biblioteca Nacional. Rio de Janeiro, n. 8, p. 2-38, 1881.

. (org.). Íris clássico. Rio de Janeiro: Tip. Univ. de Laemmert, 1860.

. (org.). Fernão Mendes Pinto. Excerptos, seguidos de uma notícia sobre a sua vida e obras um juízo crítico, apreciações de belezas e defeitos, e estudos de língua. Rio de Janeiro: Garnier, 1865.

. (org.). Manuel Maria du Bocage. Excerptos seguidos de uma notícia sobre sua vida e obras, um juízo crítico, apreciações de belezas e defeitos, estudos de língua. Rio de Janeiro/ Paris: Garnier/ A. Durand, 1867.

. Ortografia portuguesa missão dos livros elementares. Rio de Janeiro: Tip. e Livr. B. X. Pinto de Sousa, 1860.

. "Farsália": canto I. Diário oficial do Império do Brasil. Rio de Janeiro, n. 256, p. 3/ n. 257, p. 3/ n. 260, p. 3-4, 1864.

. Poema de Lucano, traduzido em português. "Farsália", canto VI. Diário do Rio de Janeiro. Rio de Janeiro, ano XLIV, n. 297, p. 2/ n. 299, p. 2, 1864.

OVÍDIO. Arte de amar de Publio Ovidio Nasão. Tradução de A. F. de Castilho seguida de comentários de J. F. de Castilho. Rio de Janeiro: Laemmert, 1862.

Os amores de P. Ovídio Nasão. Paráfrase por Antonio Feliciano de Castilho, seguida pela Grinalda Ovidiana, por José Feliciano de Castilho. Rio de Janeiro: Bernardo Xavier Pinto de Sousa, 1858.

HORÁCIO. Arte poética. Introdução, tradução e notas de R. M. Rosado Fernandes. Lisboa: Livraria Clássica, 197... 
de MENEZES, R. Dicionário literário brasileiro. Rio de Janeiro: Liv. téc. e cient., 1978.

MESQUITA, A. (org.) O livro de ouro da poesia universal. 30 séculos de poesia do século IX a.C. até o século XX. Rio de Janeiro: Ediouro, 1988.

. Poesia. São Paulo: W. M. Jackson, 1956.

OVÍDIO. Arte de amar. Prefácio de Z. de A. Cardoso, tradução de N. Correia e D. Mourão-Ferreira, apêndice com a tradução erudita de A. F. Castilho. São Paulo: Ars poetica, 1992.

. Obras; Os Fastos; Os amores; A arte de amar. Tradução de A. F. Castilho. São Paulo: Edições Cultura, 1945.

TREVIZAM, M. Líricos greco-romanos em Portugal: algumas traduções de Almeida Garrett e Antônio Feliciano de Castilho. Revista do Centro de Estudos Portugueses. Belo Horizonte, n. 27, p. 181-202, 2007.

VEYNE, P. A elegia erótica romana. Tradução de M. M. Nascimento e M. G. de S. Nascimento. São Paulo: Brasiliense, 1985.

VIANNA, H. Um intelectual português na corte de D. Pedro II: José Feliciano de Castilho Barreto e Noronha. Brasília. Coimbra, vol. V, p. 465-85, 1950.

VIEIRA, B. V. G. José Feliciano de Castilho e a clâmide romana de Machado de Assis. Machado de Assis em linha. Rio de Janeiro, vol. IV, p. 1-16, 2009.

VIRGÍlLIO. Eneida brasileira. Traduction par M. de O. Mendes. Paris: Tip. W. Remquet et Cie., 1858. 